\title{
Anticoagulation Patterns in Patients with Atrial Fibrillation Following Percutaneous Coronary Intervention in an Academic Center
}

\author{
AKASH RUSIA, MD, ${ }^{1}$ KENNETH Y. KITA, MD, ${ }^{1}$ SHAWN D. SHAH, MD, ${ }^{1}$ DIPAYON ROY, MD, ${ }^{1}$ \\ YOUNING ZHANG, MD, ${ }^{1}$ JONATHAN NATTIV, MD, ${ }^{1}$ NATASHA DOSHI, BS, ${ }^{1}$ HAN TUN, MPH, MBBS, ${ }^{1}$ \\ LEONARDO C. CLAVIJO, MD, ${ }^{1}$ and RAHUL N. DOSHI, MD ${ }^{1}$
}

${ }^{1}$ Keck School of Medicine, University of Southern California, Los Angeles, CA, USA

\begin{abstract}
A common dilemma facing physicians treating patients with atrial fibrillation $(A F)$ who have undergone percutaneous coronary intervention (PCI) is the management of oral anticoagulation (OAC) therapy, because there is also an indication for dual antiplatelet therapy in these patients. The purpose of this study was therefore to evaluate anticoagulation patterns in this patient population in an attempt to identify patterns of risk factors that may influence OAC prescribing habits. This retrospective study entailed a review of a total of 4,648 patients from two academic hospitals who underwent PCI between 2008 and 2016. We ultimately included 211 patients who had $A F$ and an indication for OAC. Chart review revealed patients' risk factors, $\mathrm{CHA}_{2} \mathrm{DS}_{2}-$ VASc and HAS-BLED scores, and antithrombotic regimens. Only 105 (49.8\%)

patients who met the indications for OAC were actually placed on OAC post-PCI. There was no significant relationship between discharge on OAC and HAS-BLED score $(t=0.14 ; p=0.44)$ or $\mathrm{CHA}_{2} D S_{2}$-VASc score $(t=0.76 ; p=0.22)$. Patients younger than 65 years of age were prescribed more triple therapy $(56 \%$ versus $33 \%$; $p<0.01)$ or any OAC $(69 \%$ versus $41 \% ; p<0.01)$ on discharge in comparison with patients 65 years of age or older. The older patient group had a significantly higher average $\mathrm{CHA}_{2} D S_{2}$-VASc score $(4.4$ versus $3.2 ; p<0.01)$ and a higher average $H A S-B L E D$ score $(2.8$ versus $2.4 ; p<0.01)$. Ultimately, this study indicated that less than half of $A F$ patients with an indication for $O A C$ were placed on $O A C$ post- $P C I$. There was no association between discharge on $\mathrm{OAC}$ and $\mathrm{CHA}_{2} D S_{2}$-VASc score, HAS-BLED score, or any other individual risk factor, with the exception of age.
\end{abstract}

KEYWORDS. Anticoagulation, atrial fibrillation, coronary intervention, dual antiplatelet therapy.
ISSN 2156-3977 (print) ISSN 2156-3993 (online) CC BY 4.0 license

(C) 2019 Innovations in Cardiac Rhythm Management

\section{Introduction}

Atrial fibrillation (AF) is the most common sustained arrhythmia, ${ }^{1}$ and thromboembolic prophylaxis is a mainstay in the clinical management of its most debilitating

\footnotetext{
The authors report no conflicts of interest for the published content. Manuscript received October 31, 2018. Final version accepted December 6, 2018.

Address correspondence to: Rahul N. Doshi, MD, Keck USC School of Medicine, 1510 San Pablo Street, Suite 320, Los Angeles, CA 90033,

USA. Email: rahul.doshi@med.usc.edu.
}

complication-stroke. Meanwhile, percutaneous coronary intervention (PCI) is one of the most commonly performed cardiovascular procedures, with more than 500,000 PCI procedures performed annually in the United States alone. ${ }^{2}$ As a result, a common dilemma faced by many physicians is the management of AF and oral anticoagulation $(\mathrm{OAC})$ in post-PCI patients who also require dual antiplatelet therapy (DAPT).

A lack of strong evidence and consensus regarding the optimal combination of therapies has led to many different philosophies and treatment strategies, including 
some based on $\mathrm{CHA}_{2} \mathrm{DS}_{2}$-VASc and HAS-BLED scores, which stratify thromboembolic risk and bleeding risk, respectively. ${ }^{3,4}$ The 2013 What is the Optimal Antiplatelet and Anticoagulant Therapy in Patients With OAC and Coronary Stenting (WOEST) trial provided some insight into the safety of the two strategies by randomizing patients with AF undergoing PCI to triple therapy (OAC and DAPT) versus double therapy (OAC and clopidogrel). ${ }^{5}$ Results from this investigation indicated that double therapy was associated with a significant reduction in bleeding complications and led to a class IIb recommendation in the 2014 American Heart Association/ American College of Cardiology/Heart Rhythm Society (AHA/ACC/HRS) AF guidelines, where it was noted that it may be reasonable to use double instead of triple therapy in this specific patient group. ${ }^{6}$

Several other studies including Safety and Efficacy of Six Months Dual Antiplatelet Therapy After Drug-eluting Stenting (ISAR-SAFE) and Triple Therapy in Patients on OAC After Drug-eluting Stent Implantation (ISAR-TRIPLE) have suggested that a shorter duration of DAPT after PCI may be acceptable and could help to reduce bleeding events. ${ }^{7,8}$ In 2018, a meta-analysis comparing double and triple antithrombotic therapy in patients with $\mathrm{AF}$ who underwent PCI found roughly similar rates of thromboembolism but a $47 \%$ increase in thrombolysis in myocardial infarction major or minor bleeding for patients receiving triple therapy. ${ }^{9}$ Although a number of investigations have attempted to identify a regimen that can maximize thromboembolic and stent thrombosis prophylaxis while minimizing bleeding risk, the lack of corroborating evidence has largely left physicians with underwhelming guidance.

Regardless of the data presented, however, practitioners and patients alike are biased in their decision-making when it comes to anticoagulation in $\mathrm{AF}^{10}$ This leads to a phenomenon of suboptimal prescription of OAC in patients with $\mathrm{AF}^{11}$ despite overwhelming evidence demonstrating associated benefits. ${ }^{12-17}$ Given the suboptimal rate of anticoagulation of AF patients on the whole, it is reasonable to suspect that the subset of patients who are also undergoing PCI would similarly have a suboptimal rate of anticoagulation.

In the present research, we reviewed the prescribing habits for patients with AF undergoing PCI to dissect the potential reasons for this and to identify patterns of risk factors that may influence anticoagulation prescribing habits. Our hypothesis was that there would be a correlation between stroke OAC prescription and risk, bleeding risk, or certain other risk factors.

\section{Methods}

From January 2008 to April 2016, 4,648 PCIs were performed at the Los Angeles County and University of Southern California Medical Center and the Keck Hospital of the University of Southern California. A retrospective chart review was performed for each patient with special attention paid to medications and problem lists on admission and discharge. This evaluation revealed 224 patients with AF undergoing PCI and appropriate documentation of their antithrombotic regimen on admission and discharge. We then were able to create a database of these patients including their demographics, medication lists, and risk factors.

The $\mathrm{CHA}_{2} \mathrm{DS}_{2}$-VASc score was calculated for each of the 224 patients to establish indications for OAC. Thirteen patients did not meet indications for anticoagulation and were given a score of less than two points. Of the remaining 211 patients, a HAS-BLED score was calculated to assess bleeding risk. The antithrombotic regimen of each patient on discharge was evaluated to assess for correlation with $\mathrm{CHA}_{2} \mathrm{DS}_{2}$-VASc score, HAS-BLED score, individual thromboembolic risk factors, or antithrombotic regimen prior to $\mathrm{PCI}$, respectively. An independent samples t-test was conducted to compare $\mathrm{CHA}_{2} \mathrm{DS}_{2}$-VASc and HAS-BLED scores for discharge regimens with and without OAC. A chi-squared test was used to assess the relationship between discharge antithrombotic regimen and each individual risk factor.

\section{Results}

Of the $211 \mathrm{AF} / \mathrm{PCI}$ patients who met indications for OAC, 105 (49.8\%) were placed on OAC post-PCI. Overall, $97(46.0 \%)$ patients were placed on DAPT only, $85(40.3 \%)$ were given triple therapy, and 19 patients $(9.0 \%)$ were given a combination of $\mathrm{OAC}$ and a single antiplatelet agent (Figure 1). Patient characteristics and demographics are summarized in Table 1. Of the patients who

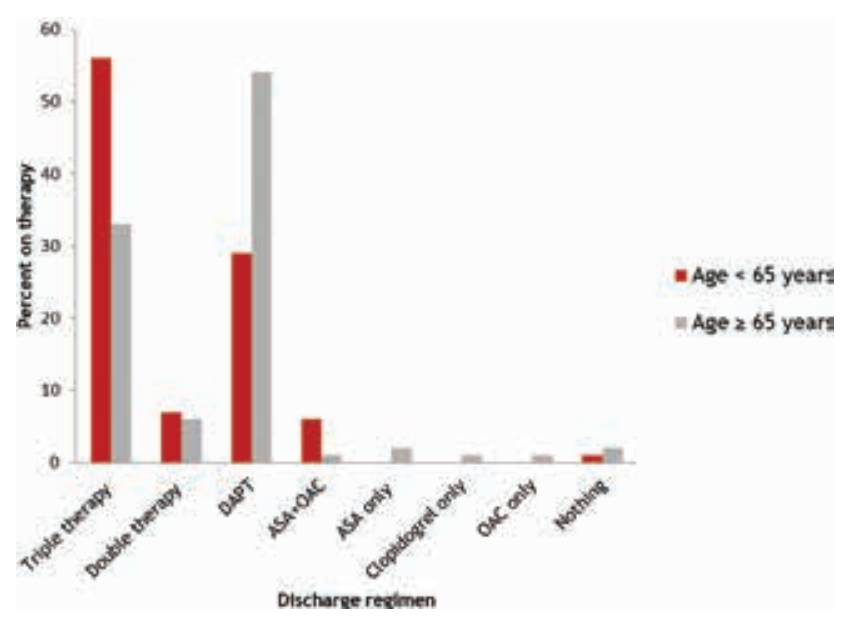

Figure 1: Antithrombotic regimen in patients with AF undergoing $\mathrm{PCl}(n=211)$. Overall, $46.0 \%$ of patients were discharged with DAPT, while $40.3 \%$ were discharged with triple therapy. When stratified by age, there were significantly more patients younger than 65 years of age who were prescribed triple therapy or any regimen that included OAC as compared with patients older than 65 years of age. Expectedly, the reverse was true for DAPT: patients who were older than 65 years of age were prescribed significantly more DAPT than those who were younger than 65 years of age. ASA: aspirin; DAPT: dual antiplatelet therapy; OAC: oral anticoagulation. 
Table 1: Patient Characteristics

\begin{tabular}{|c|c|c|c|c|c|}
\hline \multirow{2}{*}{\multicolumn{2}{|c|}{ Characteristic }} & \multirow{2}{*}{$\begin{array}{c}\text { Total } \\
\text { Patients } \\
(\mathrm{n}=211)\end{array}$} & \multicolumn{3}{|c|}{ Discharge Regimen } \\
\hline & & & $\begin{array}{c}\text { Any Regimen with } \\
\text { OAC }[n=105(49.8 \%)]\end{array}$ & $\begin{array}{c}\text { No OAC } \\
{[n=106(50.2 \%)]}\end{array}$ & $\begin{array}{c}\text { Triple Therapy } \\
{[\mathrm{n}=\mathbf{8 5}(\mathbf{4 0 . 3 \% ) ]}}\end{array}$ \\
\hline \multicolumn{2}{|c|}{ Average age, years } & $70.3 \pm 11.0$ & $68.0 \pm 11.6$ & $72.6 \pm 10.0$ & $68.0 \pm 11.6$ \\
\hline \multirow{3}{*}{ Age, $\mathrm{n}(\%)$} & $<65$ years & $68(32.2)$ & $47(44.8)$ & $21(19.6)$ & $38(44.7)$ \\
\hline & $65-75$ years & $72(34.1)$ & $27(25.7)$ & $45(42.1)$ & $22(25.9)$ \\
\hline & $>75$ years & $71(33.6)$ & $31(29.5)$ & $40(37.4)$ & $25(29.4)$ \\
\hline \multicolumn{2}{|c|}{ Female gender, n (\%) } & $45(21.0)$ & $20(19.0)$ & $25(23.4)$ & $16(18.8)$ \\
\hline \multicolumn{2}{|c|}{ Heart failure, n (\%) } & $120(56.0)$ & $61(58.7)$ & $59(55.7)$ & $47(55.3)$ \\
\hline \multicolumn{2}{|c|}{ Hypertension, n (\%) } & $171(81.0)$ & $87(82.9)$ & $84(79.2)$ & $69(81.2)$ \\
\hline \multicolumn{2}{|c|}{ Diabetes mellitus, $\mathrm{n}(\%)$} & $122(57.8)$ & $59(56.2)$ & $63(59.4)$ & $46(54.1)$ \\
\hline \multicolumn{2}{|c|}{ Stroke/TIA, n (\%) } & $27(12.8)$ & $17(16.2)$ & $10(9.4)$ & $15(17.6)$ \\
\hline \multicolumn{2}{|c|}{ Vascular disease, n (\%) } & $117(55.5)$ & $56(53.3)$ & $61(57.5)$ & $45(52.9)$ \\
\hline \multicolumn{2}{|c|}{$\mathrm{CHA}_{2} \mathrm{DS}_{2}$-VASc score } & $4.0 \pm 1.4$ & $4.0 \pm 1.3$ & $3.9 \pm 1.4$ & $4.1 \pm 1.3$ \\
\hline \multicolumn{2}{|c|}{ HAS-BLED score } & $2.7 \pm 1.1$ & $2.7 \pm 1.1$ & $2.7 \pm 1.1$ & $2.7 \pm 1.1$ \\
\hline
\end{tabular}

OAC: oral anticoagulation; TIA: transient ischemic attack.

received $\mathrm{OAC}$, six specifically were placed on direct $\mathrm{OAC}$ (DOAC) therapy.

There was no significant difference between discharge regimens with and without $\mathrm{OAC}$ for either $\mathrm{CHA}_{2} \mathrm{DS}_{2}-$ VASc scores $(4.05 \pm 1.30$ versus $3.91 \pm 1.40 ; \mathrm{t}=0.76$; $\mathrm{p}=0.22)$ or HAS-BLED score $(2.69 \pm 1.11$ versus $2.71 \pm 1.12 ; \mathrm{t}=0.14 ; \mathrm{p}=0.44)$. These results suggest that neither $\mathrm{CHA}_{2} \mathrm{DS}_{2}$-VASc score (Figure 2) nor HAS-BLED score have an effect on whether or not patients were discharged on OAC. Regarding the individual risk factors, no association was found between discharge on OAC and congestive heart failure, systemic hypertension, vascular disease, female gender, or diabetes mellitus (Table 2). Although there was a trend toward association, a history of stroke or transient ischemic attack was

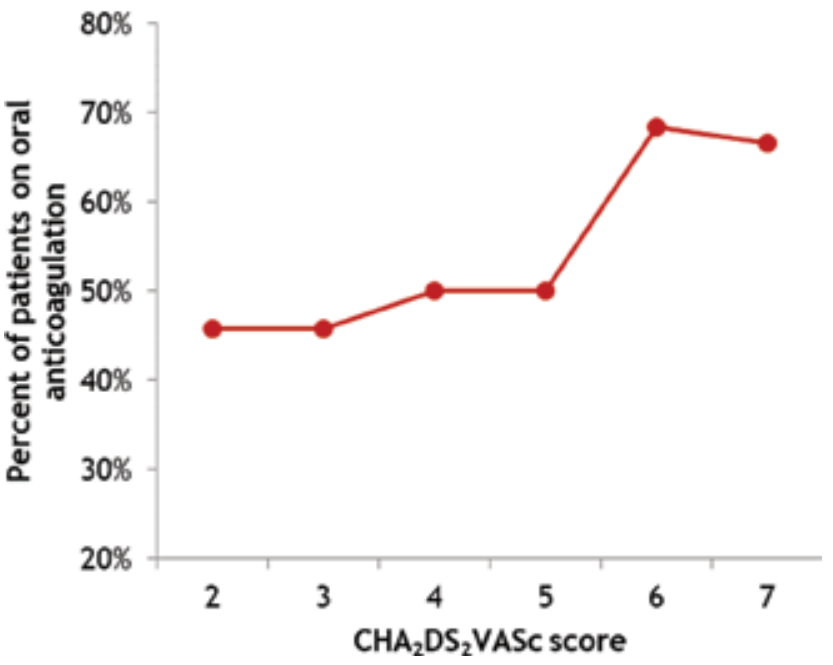

Figure 2: Percentage of patients with $\mathrm{AF}$ undergoing $\mathrm{PCl}$ who were prescribed oral anticoagulation on discharge for each $\mathrm{CHA}_{2} \mathrm{DS}_{2}$-VASc score. also not significantly associated with discharge on OAC $(\mathrm{p}=0.14)$.

Patients who were younger than 65 years of age (average age: 57.9 years) were more likely to be anticoagulated than patients who were 65 years of age or older (average age: 76.2 years). Furthermore, the younger patients were prescribed more triple therapy $(56 \%$ versus $33 \%$; $p<0.01$ ) or any OAC $(69 \%$ versus $41 \%$; $p<0.01)$ on discharge. Conversely, the older patient group had a significantly higher average $\mathrm{CHA}_{2} \mathrm{DS}_{2}$-VASc score (4.4 versus 3.2; $\mathrm{p}<$ 0.01 ) and a significantly higher HAS-BLED score (2.8 versus 2.4; $\mathrm{p}<0.01)$. Expectedly, if a patient was admitted on $\mathrm{OAC}$, they were more likely to be discharged with OAC $(\mathrm{p}<0.01)$.

\section{Discussion}

The most feared and debilitating complication of nonvalvular AF is stroke. The rate of stroke in this population averages approximately $5 \%$ per year, or two to seven times the rate in those without nonvalvular $\mathrm{AF}^{18}$ The mainstay of stroke risk management remains anticoagulation; however, the inherent risk of bleeding is a concern that has consistently led to the inconsistent management of cerebrovascular accident (CVA) risk. Nowhere is this more evident than in those patients with $\mathrm{AF}$ who are post-PCI and who require DAPT and OAC.

The current study has shown that only half of the study participants who met the indication for OAC for AF following PCI were actually placed on OAC. We found no correlation when we delved into whether clinical risk factors such as a history of CVA, $\mathrm{CHA}_{2} \mathrm{DS}_{2}$-VASc score, or HAS-BLED score correlated with the decision to discharge patients on OAC. In fact, the only two factors that had a statistically significant association with OAC on discharge were whether a patient was already on OAC prior to PCI and if they were younger than 65 years of 
Table 2: Patients on Oral Anticoagulation with Presence or Absence of Risk Factors

\begin{tabular}{|l|l|l|l|}
\hline \multicolumn{1}{|c|}{ Risk Factor } & $\begin{array}{c}\text { Patients with Risk Factor } \\
\text { in Question Who Were } \\
\text { Prescribed OAC }\end{array}$ & $\begin{array}{c}\text { Patients Without Risk Factor } \\
\text { in Question Who Were } \\
\text { Prescribed OAC }\end{array}$ & p-value \\
\hline Congestive heart failure & $51 \%$ & $48 \%$ & 0.72 \\
\hline Hypertension & $51 \%$ & $45 \%$ & 0.50 \\
\hline Vascular disease & $48 \%$ & $52 \%$ & 0.53 \\
\hline Diabetes mellitus & $48 \%$ & $52 \%$ & 0.55 \\
\hline Prior stroke or TIA & $63 \%$ & $48 \%$ & 0.14 \\
\hline Age $<65$ years & $69 \%$ & $41 \%$ & 0.01 \\
\hline
\end{tabular}

OAC: oral anticoagulation; TIA: transient ischemic attack.

age. These findings are in line with what's expected in a community of physicians who lack a consensus on how to manage such individuals. Moreover, these findings seem to confirm that physicians continue to base decisions on clinical gestalt rather than on strong data supporting OAC in the context of either triple or double therapy. This is due in part to weak direction from guidelines.

Our study found that younger AF patients had a lower stroke risk and were more likely to be anticoagulated than older AF patients, which confirms prior findings. ${ }^{19}$ A review by Bungard et al. in 2000 found that physicians generally base their decision to anticoagulate older AF patients on the perceived risk of embolism and hemorrhage. ${ }^{10}$ Some surveyed physicians, however, noted that they have withheld anticoagulation in patients based on the belief that patients may refuse treatment or may not be compliant, although there is evidence that, when given the choice, most patients would comply with treatment. ${ }^{20}$ Nevertheless, a reduced stroke risk generally far outweighs the risk of major hemorrhage while on anticoagulation and most concerns about bleeding are generally unfounded. ${ }^{21}$ Simply put, the oldest patients with AF are those who have the highest risk of stroke and the most to gain from anticoagulation. While the risk of falls is in many cases the documented reason for withholding anticoagulation, several analyses have shown that warfarin still has a significant net protective effect against composite outcomes of out-of-hospital death or hospitalization for stroke, myocardial infarction, or hemorrhage. ${ }^{22}$ Evidence points to focusing on maintaining international normalized ratio (INR) values of 2.0 to 3.0 (therapeutic range) and ensuring proper blood pressure control as a means of mitigating intracranial hemorrhage risk, as opposed to withholding anticoagulation. ${ }^{23,24}$

Our data were not powered enough to detect a difference in prescribing habits between warfarin and DOACs, as only six of the 105 patients who received OAC received a DOAC specifically. We have seen an increase in the use of DOACs as compared with warfarin; some studies have even shown a resulting increase in the overall percentage of AF patients receiving OAC. ${ }^{25} \mathrm{~A}$ meta-analysis of four existing major randomized control trials for DOACs showed a significant reduction in stroke, intracranial hemorrhage, and mortality (albeit with increased gastrointestinal bleeding) in comparison with warfarin. ${ }^{26}$ In real-world use, compliance rates are generally similar between warfarin and DOACs; however, warfarin requires INR monitoring, which allows physicians to directly see where noncompliance may be an issue. ${ }^{27}$ The highest thromboembolic risk appears to be among patients who are not compliant with DOAC therapy. Nevertheless, with more AF patients being prescribed anticoagulation in the post-DOAC era, it will be of interest to see whether long-term rates of thromboembolism show strong improvement.

The findings of this study were based on patient data from 2008 to 2016; however, in more recent years, landmark trials have shown that treatment with OAC and a P2Y12 inhibitor may perhaps be safer and noninferior in terms of efficacy. $5,6,9$ Thus, a limitation of this study relates to the fact that trends in prescribing habits are expected to change with double therapy regimens being increasingly utilized. This study was also limited due its retrospective design and the quality of the data retrieved from electronic records being beholden to the accuracy of the documenting physician. Future studies in this arena could also elicit more explicit information as to why providers chose one regimen over another or why patients were not able to tolerate OAC; this may provide a clearer picture of the reasons for the suboptimal prescription of $\mathrm{OAC}$ in patients with $\mathrm{AF}$.

\section{Conclusions}

Less than half of patients who met indications for OAC for AF after PCI were discharged on appropriate therapy. Patients were more likely to be discharged on OAC if they were already on OAC at the time of admission or if they were younger than 65 years old. There was no association between discharge on $\mathrm{OAC}$ and $\mathrm{CHA}_{2} \mathrm{DS}_{2}-$ VASc score, HAS-BLED score, or any other individual risk factor, with the exception of age. This study ultimately presents three observations, as follows: (1) there are major gaps in treating physicians' perceptions of the scientific consensus on how to treat AF patients undergoing PCI; (2) there is a lack of established guidelines to direct community physicians; and (3) there remains a stigma regarding treating older patients with anticoagulation. 


\section{References}

1. January CT, Wann LS, Alpert JS, et al. 2014 AHA/ACC/ HRS guideline for the management of patients with atrial fibrillation: a report of the American College of Cardiology / American Heart Association Task Force on Practice Guidelines and the Heart Rhythm Society. J Am Coll Cardiol. 2014;64(21):e1-e76.

2. Stuntz M, Palak A. Recent trends in percutaneous coronary intervention volume in the United States. Value Health. 2016;19:A641.

3. Lip GY, Frison L, Halperin JL, Lane DA. Comparative validation of a novel risk score for predicting bleeding risk in anticoagulated patients with atrial fibrillation: the HASBLED (Hypertension, Abnormal Renal/Liver Function, Stroke, Bleeding History or Predisposition, Labile INR, Elderly, Drugs/Alcohol Concomitantly) score. J Am Coll Cardiol. 2011;57(2):173-180.

4. Lip GY, Nieuwlaat R, Pisters R, Lane DA, Crijns HJ. Refining clinical risk stratification for predicting stroke and thromboembolism in atrial fibrillation using a novel risk factor-based approach: the euro heart survey on atrial fibrillation. Chest. 2010;137(2):263-272.

5. Dewilde WJ, Oirbans T, Verheugt FW. Use of clopidogrel with or without aspirin in patients taking oral anticoagulant therapy and undergoing percutaneous coronary intervention: an open-label, randomised, controlled trial. Lancet. 2013;381(9872):1107-1115.

6. January CT, Wann LS, Alpert JS, et al. 2014 AHA/ACC/HRS guideline for the management of patients with atrial fibrillation. Circulation. 2014;130(23):e199-e267.

7. Fiedler KA, Maeng M, Mehilli J, et al. Duration of triple therapy in patients requiring oral anticoagulation after drug-eluting stent implantation: the ISAR-TRIPLE trial. J Am Coll Cardiol. 2015;65(16):1619-1629.

8. Schulz-Schüpke S, Byrne RA, Ten Berg JM, et al. ISAR-SAFE: a randomized, double-blind, placebo-controlled trial of $6 \mathrm{vs}$. 12 months of clopidogrel therapy after drug-eluting stenting. Eur Heart J. 2015;36(20):1252-1263.

9. Golwala HB, Cannon CP, Steg PG, et al. Safety and efficacy of dual vs. triple antithrombotic therapy in patients with atrial fibrillation following percutaneous coronary intervention: a systematic review and meta-analysis of randomized clinical trials. Eur Heart J. 2018;39(19):1726-1735a.

10. Bungard TJ, Ghali WA, Teo KK, McAlister FA, Tsuyuki RT. Why do patients with atrial fibrillation not receive warfarin?. Arch Intern Med. 2000;160(1):41-46.

11. Ogilvie IM, Newton N, Welner SA, Cowell W, Lip GY. Underuse of oral anticoagulants in atrial fibrillation: a systematic review. Am J Med. 2010;123(7):638-645.

12. Connolly SJ, Laupacis A, Gent M, Roberts RS, Cairns JA, Joyner C. Canadian atrial fibrillation anticoagulation (CAFA) study. J Am Coll Cardiol. 1991;18(2):349-355.

13. European Atrial Fibrillation Trial Study Group. Secondary prevention in non-rheumatic atrial fibrillation after transient ischaemic attack or minor stroke. Lancet. 1993;342(8882): 1255-1262.
14. Ezekowitz MD, Bridgers SL, James KE, et al. Warfarin in the prevention of stroke associated with nonrheumatic atrial fibrillation. Veterans Affairs Stroke Prevention in Nonrheumatic Atrial Fibrillation Investigators. N Engl J Med. 1992;327(20):1406-1412.

15. Petersen P, Boysen G, Godtfredsen J, Andersen ED, Andersen B. Placebo-controlled, randomised trial of warfarin and aspirin for prevention of thromboembolic complications in chronic atrial fibrillation: the Copenhagen AFASAK study. Lancet. 1989;1(8631):175-179.

16. Stroke Prevention in Atrial Fibrillation Investigators. Stroke prevention in atrial fibrillation study: final results. Circulation. 1991;84(2):527-539.

17. Boston Area Anticoagulation Trial for Atrial Fibrillation Investigators, Singer DE, Hughes RA, et al. The effect of low-dose warfarin on the risk of stroke in patients with nonrheumatic atrial fibrillation. N Engl J Med. 1990;323(22): 1505-1511.

18. Harrington AR, Armstrong EP, Nolan PE Jr., Malone DC. Cost-effectiveness of apixaban, dabigatran, rivaroxaban, and warfarin for the prevention of stroke prophylaxis in atrial fibrillation. Stroke. 2013;44(6):1676-1681.

19. McCrory DC, Matchar DB, Samsa G, Sanders LL, Pritchett EL. Physician attitudes about anticoagulation for nonvalvular atrial fibrillation in the elderly. Arch Intern Med. 1995;155(3):277-281.

20. Gottlieb LK, Salem-Schatz S. Anticoagulation in atrial fibrillation: does efficacy in clinical trials translate into effectiveness in practice? Arch Intern Med. 1994;154(17):1945-1953.

21. Man-Son-Hing M, Laupacis A. Anticoagulant-related bleeding in older persons with atrial fibrillation: physicians' fears often unfounded. Arch Intern Med. 2003;163(13):1580-1586.

22. Gage BF, Birman-Deych E, Kerzner R, Radford MJ, Nilasena DS, Rich MW. Incidence of intracranial hemorrhage in patients with atrial fibrillation who are prone to fall. Am J Med. 2005;118(6):612-617.

23. Fihn SD, Callahan CM, Martin DC, McDonell MB, Henikoff JG, White RH. The risk for and severity of bleeding complications in elderly patients treated with warfarin. The National Consortium of Anticoagulation Clinics. Ann Intern Med. 1996;124(11):970-979.

24. Fang MC, Chang Y, Hylek EM, et al. Advanced age, anticoagulation intensity, and risk for intracranial hemorrhage among patients taking warfarin for atrial fibrillation. Ann Intern Med. 2004;141(10):745-752.

25. Baker D, Wilsmore B, Narasimhan S. Adoption of direct oral anticoagulants for stroke prevention in atrial fibrillation. Intern Med J. 2016;46(7):792-797.

26. Ruff CT, Giugliano RP, Braunwald E, et al. Comparison of the efficacy and safety of new oral anticoagulants with warfarin in patients with atrial fibrillation: a meta-analysis of randomised trials. Lancet. 2014;383(9921):955-962.

27. Lakkireddy DJ, Karst E, Mahapatra S, Winterfield J, Roberts G, Mansour M. TCT-53 thromboembolic event rate is elevated with lower adherence to warfarin and NOACs. J Am Coll Cardiol. 2016;68(18):B22. 